внесении корректировок в отчетность, владельцы и другие заинтересованные лица должны быть проинформированы о процессе корректировки.

Таким образом, если в фирме учет ведется не по МСФО, то у нее есть возможность вносить изменения в собственную учетную политику и отражать подобные события в отчетности другим способом, который отвечает их внутренней политике в части достоверного и обоснованного учета. А в соответствии с МСФО №10 организации необходимо учитывать события после отчетного периода исключительно в соответствии с правилами и рекомендациями, указанными в нем.

$$
* * *
$$

1. Агеева О.А. Международные стандарты финансовой отчетности: Учебник / О.А. Агеева, А.Л. Ребизова. М.: Юрайт, 2016. 567 с.

2. Алисенов А.С. Международные стандарты финансовой отчетности: Учебник / А.С. Алисенов. - М.: Юрайт, 2017. $157 \mathrm{c}$.

3. Бабаев Ю.А. Международные стандарты финансовой отчетности (МСФО): Учебник / Ю.А. Бабаев, А.М. Петров. - М.: Вузовский учебник, 2018. 188 с.

4. Брызгалов Д.В. Международные стандарты финансовой отчетности / Д.В. Брызгалов, Н.В. Кириллова, А.А. Цыганов. - М.: КноРус, 2016. 328 с.

5. Гетьман В.Г. Международные стандарты финансовой отчетности: Учебник / В.Г. Гетьман, Л.В. Сотникова, М.А. Вахрушина. - М.: Инфра-М, 2018. 60 с.

6. Карагод В.С. Международные стандарты финансовой отчетности: Учебник / В.С. Карагод, Л.Б. Трофимова. - М.: Юрайт, 2016. 122 с.

7. Куликова Л.И. Международные стандарты финансовой отчетности: Учебное пособие / Л.И. Куликова. - М.: Магистр, 2017. 174 с.

8. Миславская Н.А. Международные стандарты финансовой отчетности и унификация учетных систем / Н.А. Миславская. - М.: Русайнс, 2018. 284 с.

\title{
Донченко В.К. \\ Развитие рыночных отношений в отходоперерабатывающей отрасли Российской Федерации
}

ФГБУН «Санкт-Петербургский Федеральный исследовательский центр Российской академии наук» (Россия, Санкт-Петербург)

doi: 10.18411/trnio-10-2021-140

\section{Аннотация}

В статье раскрываются процессы развития рыночных отношений в отходоперерабатывающей отрасли Российской Федерации.

Ключевые слова: твердые коммунальные отходы, отходоперерабатывающая промышленность, региональный экологический оператор, вторичное сырье, рынки вторичного сырья.

\section{Abstract}

The article reveals the processes of development of market relations in the waste processing industry of the Russian Federation.

Keywords: solid municipal waste, waste processing industry, regional environmental operator, secondary raw materials, secondary raw materials markets.

\section{1. Введение}

Современная экономика природопользования становится частью циркулярной экономики [1]. В которой развивается научная концепция, согласно которой отходы - это вторичные ресурсы, которые в циркулярной экономике максимально перерабатываются во вторичное сырье. Вторичное сырье сертифицируется и представляет собой товарную продукцию, которая реализуется на различных сырьевых рынках. На сырьевых рынках 
вторичное сырье вступает в конкуренцию с сырьем, произведенным из природных ресурсов. Этот новый вид конкурентных отношений на сырьевых рынках инициирует новую проблемную ситуацию, научная разработка которой представляет собой активно развивающееся направление в экономике природопользования. Сокращение природоемкости хозяйственной и иной деятельности с одновременным ростом экологической емкости территорий хозяйственного освоения представляет собой главный принцип экологической политики Российской Федерации.

В настоящее время проблема обращения с отходами производства и потребления в Российской Федерации относится к числу приоритетных.

Институционально это закреплено в федеральных и региональных законах, а также в подзаконных нормативно-правовых актах.

Переход Российской Федерации на новую политику в экономике природопользовании стимулировал создание в стране отходоперерабатывающей отрасли промышленности.

Одним из основных ресурсов для функционирования данной отрасли являются твердые коммунальные отходы (ТКО). Использование промышленных технологий позволит коренным образом изменить негативную ситуацию в системе обращения с отходами производства и потребления.

Для изменения сложившейся ситуации была поставлена стратегическая государственная задача по созданию в национальной экономической системе отходоперерабатывающей отрасли промышленности, реализующей политику экономики замкнутого цикла.

Вполне понятно, что при переходе на промышленные технологии переработки ТКО с использованием наилучших доступных технологий (НДТ), мы надеемся резко сократить их поступление на полигоны, исключить образование несанкционированных свалок и получить полезную продукцию для включения ее в хозяйственный оборот [2,3].

Вышеизложенное обусловило актуальность проведения исследования с целью научного обоснования институциональных процессов в экономике природопользования, обеспечивающих инвестиционную привлекательность деятельности в отходоперерабатывающей отрасли промышленности и развития региональных рынков товаров из вторичного сырья, полученного на различных технологических стадиях переработки ТКО.

Федеральным законом № 404-Ф3 от 29.10.2015 [4] были внесены изменения в ряд законодательных актов, касающихся защиты окружающей среды и утилизации ТКО, в частности, вывоз ТКО был переведен из сферы жилищных услуг в сферу коммунальных услуг. Плата за вывоз ТКО включена отдельной строкой в платежные документы за коммунальные услуги. Данное институциональное положение было направлено на упорядочение системы обращения с ТКО на начальной стадии. Считалось (однако обоснования пока нет), что взимание платы за услугу по вывозу ТКО от конкретных абонентов - первоначальных владельцев ТКО решает проблему о переходе прав собственности к Региональному оператору по обращению с ТКО.

В соответствии с законом «....Сбор, транспортирование, обработка, утилизация, обезвреживание, захоронение твердых коммунальных отходов на территории субъекта Российской Федерации обеспечиваются региональным оператором в соответствии с региональной программой в области обращения с отходами и территориальной схемой обращения с отходами».

\section{2. Материалы и методы}

Проведенный в работе [5] анализ показал, что для Региональных операторов создаются льготные условия хозяйственной деятельности на правах естественной монополии оказывающей услуги абонентам по соответствующим договорам. Известно, что замена рыночных отношений монопольными прежде всего отражается на тарифах. 
Тарифы коммунальных услуг должны быть экономически обусловлены и социально приемлемы. Именно социальная составляющая представляет собой предмет острых дискуссий, в результате которых достигается консенсус различных ветвей государственной власти, а также хозяйствующих субъектов и населения, которые являются абонентами региональной системы обращения с ТКО. В данном случае имеется ввиду дотации или иные поступления денежных средств до возможного социально приемлемого уровня региональных тарифов оплаты за коммунальную услугу по вывозу ТКО [6].

До введения института региональных операторов системы обращения с ТКО развивались по законам рынка.

В рыночной системе принципиально важным является создание и поддержание режима добросовестной конкуренции, и соблюдение антимонопольного законодательства. В международной практике к репрезентативным показателем текущего состояния конкретного рынка относится значение индекса Херфиндаля-Хиршмана (HНI) [7].

Значение HНI определяется как сумма квадратов долей каждого участника конкретного рынка. По имеющейся доступной информации мы провели анализ динамики HНI относительно ситуации в региональной системе обращения с ТКО в Ленинградской области за период с 1995 года по 2019 год, то есть до введения института регионального оператора. Полученные значения ННІ представлены в таблице 1.

Таблица 1

Текущее состояние рынка в региональной системе обращения с ТКО в Ленинградской области

\begin{tabular}{|c|c|c|}
\hline $\begin{array}{c}\text { № } \\
n / n\end{array}$ & Период оченки, ге. & Значение индекса Херфиндаля-Хиримана \\
\hline 1 & $1995-2000$ & $200-300$ \\
\hline 2. & $2000-2010$ & $300-800$ \\
\hline 3. & $2010-2018$ & $800-1900$ \\
\hline 4. & $c 2019$ & 10000 \\
\hline
\end{tabular}

Анализ динамики изменений HНI показал, что в конце девяностых годов он изменялся в интервале от 200 до 300, что свидетельствует о том, что на региональном рынке в системе обращения с ТКО в Ленинградской области участвовало много игроков и была свободная конкуренция со всеми ее плюсами и минусами.

В период с 2000 по 2010 год его значение возросло до 800, что свидетельствует о том, что количество компаний, работающих на региональном рынке в системе обращения с ТКО в результате конкуренции, сократилось. В последующий период до 2019 года значение НHI выросло до 1900, что свидетельствует об острой конкуренции основных игроков, следствием чего было формирование достаточно высокого уровня монополизации на региональном рынке в системе обращения с ТКО в Ленинградской области. При переходе на систему Регионального оператора в 2019 году он равен 10000, то есть полная монополия.

Иная ситуация имела место на рынке в системе обращения с ТКО в СанктПетербурге. С начала девяностых годов на данном рынке в основном действовали два оператора в северной и в южной части города. Значение НHI составляло 5000, что свидетельствовало об очень высокой степени монополизации рынка в городской системе обращения с ТКО. Выбор по результатам конкурса одного Регионального оператора в Санкт-Петербурге состоялся только в августе 2021 года. Победителем в конкурсе на выбор регионального оператора по обращению с отходами в городе стал АО «Невский экологический оператор» (НЭО), учредителями которого являются Санкт-Петербург, Ленинградская область, ВТБ и «Интер РАО».

Таким образом, после утверждения результатов конкурса значение HНI и по СанктПетербургу стало равно 10000, что означает полную монополию на 10 летний срок действия контракта. 


\section{3. Результаты исследования}

Результаты проведенного исследования во многом будут характерны для других городов Российской Федерации с численностью жителей более одного миллиона человек, а также для прилегающих областей, на территориях которых располагаются полигоны ТКО.

В Федеральном законе от 24.06.1998 N 89-Ф3 (с доп. от 02.07.2021) [4] в статье 24.6 на регионального оператора возлагается сбор, транспортирование, обработка, утилизация, обезвреживание, захоронение ТКО на территории субъекта Российской Федерации. В этой статье в процедурах действий регионального оператора было бы целесообразно выделить в качестве объекта правового регулирования процессы производства вторичного сырья и его сертификации в качестве товара.

На практике получение вторичного сырья из ТКО имеет место на стадиях сбора, при наличии системы раздельного сбора, обработки на мусоросортировочных комплексах, а также на стадиях обезвреживания и утилизации. Получение вторичного сырья на стадии захоронения представляет интерес как для владельцев полигонов ТКО, так и для жителей населенных пунктов, которые находятся в зоне их влияния.

Для сохранения рыночной модели обращения с ТКО целесообразно в структуру отходоперерабатывающей отрасли включить институт частных предпринимателей переработчиков сортированных отходов в сертифицированное вторичное сырье.

\section{4. Проблема создания технологических комплексов по производству вТоричного сырья из ТКО}

Законодательно в институт региональных операторов не включены функции производства и продажи вторичного сырья в системе обращения с ТКО. Руководствуясь действующим законодательством, отходы являются вторичным материальным или энергетическим ресурсом. Товаром может стать вторичное сырье, которое получается на стадии утилизации отходов. Данный вид деятельности подлежит лицензированию федеральным надзорным органом Департаментом Природопользования структурным подразделением Министерства природных ресурсов и экологии РФ. Для получения лицензии необходимо пройти несколько проверок на соответствие санитарным требованиям к земельному участку, где расположено предприятие, зданиям или строениям, а также производственному оборудованию, которое осуществляет утилизацию отходов. В связи с тем, что отход на каждом из этапов технологического цикла может стать вторичным сырьем, которое сертифицируется в качестве товара, то возникает правовая, технологическая и, как следствие, экономическая коллизия в части определения понятия «утилизация». Данное понятие охватывает практически все технологические стадии обращения с ТКО и завершается их захоронением.

Институциональная неопределенность и широкое толкование понятия «утилизация» дает нам возможность считать, что оно включает технологические комплексы по производству вторичного сырья на стадиях сбора, транспортировки, обработки, обезвреживания и захоронения ТКО.

Наличие технологических комплексов, производящих вторичное сырье в виде товарной продукции, создают условия для формирования рынков вторичного сырья.

В 2021 году продолжилось формирование структуры и уточнение функций российского экологического оператора и его региональных формирований.

Игроками на таком рынке выступают региональные экологические операторы, фактические владельцы ТКО, а также переработчики и продавцы ТКО. участники рынка вторичного сырья. , которые должны покупать ТКО, как вторичный ресурс и перерабатывать их во вторичное сырье для его реализации на различных рынках.

В региональной системе обращения с ТКО хозяйственная деятельность региональных экологических операторов и переработчиков ТКО представляет собой особую форму модели государственно-частного партнерства. В новых экономических условиях на рынках вторичного сырья возможны различные формы данной модели. 
Раскрытие проблемы формирования и процессов развития различных форм модели государственно-частного партнерства в отходоперерабатывающей отрасли на уровне отдельных регионов, а также на уровне межрегиональных взаимодействий в сфере обращения с ТКО представляет собой перспективный объект для эколого-экономических исследований.

\section{5. Стратегические индикаторы отходоперерабатывающей отрасли}

ТКО - это вторичные ресурсы, которые представляет собой исходные компоненты отходоперерабатывающей отрасли для производства сертифицированного вторичного сырья. Для реализации продукции отходоперерабатывающей отрасли на региональных и международных сырьевых рынках вторичное сырье проходит обязательную сертификацию соответствия по российским и международным стандартам.

Данная продукция реализуется на рынке, где вступает в конкуренцию с товарной продукцией, произведенной из природных ресурсов. Имеющиеся практические примеры показывают, что товары, произведенные из вторичного сырья, в настоящее время в РФ успешно конкурируют с товарами из природных ресурсов, главным образом по ценовому показателю [5].

Объемы продаж вторичного сырья должны стать стратегическим экологоэкономическим индикатором предотвращенного экологического ущерба, объективно характеризующего эколого-экономическую эффективность отходоперерабатывающей отрасли Российской Федерации. [8]. В отраслевом контексте ожидаемый результат переработки отходов будет выражаться в объемах произведенного и сертифицированного вторичного сырья, а также в объемах его продаж по видам на сырьевых рынках.

Конкурентные взаимодействия природного и вторичного сырья на сырьевых рынках представляют собой ключевую проблему экономики природопользования, раскрытие которой актуализирует разработку новой эколого-экономической политики природопользования при переходе на принципы и методы циркулярной экономики.

Следствием данной политики будет ожидаемый рост объемов государственных и частных инвестиций в отходоперерабатывающую отрасль промышленности, которые определяют величину стратегического экономического индикатора -инвестиционной привлекательности этого вида хозяйственной деятельности.

В качестве стратегического социального индикатора отходоперерабатывающей отрасли может быть представлена часть дохода от продажи вторичного сырья, направленная в региональные бюджеты на уменьшение тарифов в региональных системах обращения с TKO.

К положительным аспектам развития отходоперерабатывающей отрасли следует отнести тот факт, что произведенное из отходов вторичное сырье поддается достаточно точному статистическому учету. Причем, в отличие от статистики учета негативных воздействий на окружающую среду, к данной статистике, хозяйствующие субъекты проявляют активную заинтересованность.

Все вышеуказанные стратегические отраслевые индикаторы связаны с индикаторами систем регионального природопользования. Эта связь проявляется в том, что максимальный объем переработки отходов во вторичное сырье, его сертификация в качестве товарной продукции, которая реализуется на сырьевых рынках, позволит оценить экологоэкономическую эффективность инновационной модели региональной системы природопользования. по официально установленному сокращению негативного воздействия на окружающую среду и здоровье населения [9].

В то же время, следует отметить, что, несмотря на государственную значимость и общественную заинтересованность, формирование региональных рынков товарной продукции, произведенной из вторичного сырья, полученного на различных стадиях переработки ТКО проходит крайне медленно. Статистический учет вторичного сырья находится в стадии становления, что создает значительные трудности в исследованиях 
эколого-экономических процессов, которые имеют место на региональных рынках вторичного сырья.

Главная причина такого положения заключается в неопределенности институционального статуса отходоперерабатывающей отрасли промышленности в экономике промышленного производства и в экономике природопользования.

Общероссийским классификатором видов экономической деятельности (ОКВЭД) разработанным Минэкономразвития РФ и утвержденным Приказом Росстандарта от 31.01.2014 №14-ст конкретно отходоперерабатывающая экономическая деятельность, направленная на переработку вторичного сырья из ТКО в сертифицированную товарную продукцию пока не предусмотрена [2].

В настоящее время в ОКВЭД представлена деятельность, связанная с обращением с отходами. Так, например, в разделе Е «Водоснабжение, водоотведение, организация сбора и утилизация отходов, деятельность по ликвидации загрязнений» под кодом 38.2 «Обработка и утилизация отходов» включены следующие виды деятельности:

- $\quad$ сбор и очистка до утилизации различных видов отходов;

- $\quad$ захоронение отходов в земле или в воде;

- $\quad$ захоронение или закапывание отходов;

- утилизация использованных деталей конструкций ...;

- утилизация отходов путем сжигания или окисления;

- $\quad$ регенерация энергии путем процесса сжигания отходов.

Формулировки представленных в ОКВЭД видов деятельности в системе обращения с отходами в настоящее время не отвечают требованиям новой экологической, а по некоторым позициям противоречат ей. Так в работе [8] отмечается, что представленный в ОКВЭД вид деятельности - «захоронение отходов ... в воде» противоречит положениям Федерального закона № 89-Ф3 запрещающим, вплоть до уголовной ответственности, захоронение отходов в воде. Кроме того, представленное виды деятельности не направлены на получение вторичного сырья и производство товарной продукции. К товарной продукции предъявляются жесткие требования по различным аспектам, включая экологические. Перед поступлением на различные рынки товары, произведенные из ТКО, обязательно должны пройти процедуры сертификации. Покупатель таких товаров при наличии сертификатов, доказывающих их безопасность для окружающей среды и здоровья человека, имеет документально подтвержденные гарантии их безопасности. Нарушение гарантий безопасности дает юридические основания для обращения в суд. Поэтому при разработке новых законодательных актов необходимо предусмотреть процедуры обязательной сертификации товарной продукции отходоперерабатывающей отрасли.

\section{6. Выводы}

По результатам проведенного исследования можно сделать следующие выводы.

1. Производство вторичного сырья в функциях экологических операторов представлены в общей форме через утилизацию ТКО.

2. Отсутствие требований к сертификации вторичного сырья в качестве товарной продукции, представляет собой главное препятствие в реализации новой экологической политики в системе обращения с ТКО. В результате новый сектор экономики до настоящего времени не получил реальных экономических преимуществ, соответствующих его социальноэкологическому статусу, а без этого бизнес-структуры будут проявлять к нему свой интерес только на декларативном уровне.

3. Представленный в нашем исследовании эколого-экономический анализ проблемной ситуации на примере Санкт-Петербурга и Ленинградской области позволил обосновать стратегические индикаторы становления и развития отходоперерабатывающей отрасли промышленности в Российской Федерации. 
4. Определены экономические основания для формирования региональных рынков вторичного сырья.

5. Краткий анализ проблем создания технологических комплексов по производству вторичного сырья из ТКО показал, что особую актуальность в настоящее время имеет обоснование и включение в ОКВЭД новых видов экономической деятельности представленных в отходоперерабатывающей отрасли промышленности.

6. Актуально проведение исследований, направленных на раскрытие институциональных, экономических и экологически механизмов и инструментов, стимулирующих продвижение сертифицированного вторичного сырья на региональных и международных сырьевых рынках.

$$
* * *
$$

1. V. Donchenko, B. Boravskiy. Relevant problems of formation and development of the world market of recyclables from production and consumption wastes. - Eurasian financial and economic. HERALD. №1(9), 2020, pp. 39 - 44/

2. Бабина Ю.В. Нормативные основы и условия внедрения наилучших доступных технологий. - Справочник эколога. 2018, №4. С. 38 - 53.

3. Бегак М.В., Гусева Т.В., Боравская Т.В. и др. Наилучшие доступные технологии и комплексное экологические разрешения: перспективы применения в России. / под редакцией М.В. Бегака. - ЮрИнфоРПресс, 210. - 220c.

4. Федеральный закон от 24.06.1998 N 89-Ф3 (ред. от 29.12.2015) "Об отходах производства и потребления", Москва, Кремль , 24 июня 1998 г., ,N 89-Ф3.

5. Donchenko V.K., Shevchenko S.Y. THE SOLUTION OF CROSS-BORDER PROBLEMS OF ECOLOGICAL SAFETY IN THE WASTE MANAGEMENT INDUSTRY. Proceedings of the 2018 IEEE International Conference ", Management of Municipal Waste as an Important Factor of Sustainable Urban Development", WASTE 2018. 2018. C. 28-30.

6. Хильченко Г.В. Тарификация отрасли обращения с отходами. - В ж. «Твердые бытовые отходы», №5, 2016, c.7-9

7. Индекс Херфиндаля - Хиршмана: значение и методика расчета. [Электронный pecypc]. URL: https:// businessman.ru/new-index-xerfindalya-xirshmana-znachenie-i-melodica-rascheta.html.

8. Семилетова Е.В. Экономическая политика России: новый этап. - Русская политология. - 2017, №3. С .6-11.

9. Петрова Т.В. Правовое регулирование нормирования воздействия на окружающую среду: новые подходы и старые проблемы. - «Экологическое право». - 2018.-№5 (спец. вып.). - С. 22 - 27.

\section{Драненко Л.П. \\ Актуальные вопросы организации внутреннего аудита \\ СахИЖТ-филиал ДВГУПС \\ (Россия, Южно-Сахалинск)}

doi: 10.18411/trnio-10-2021-141

\section{Аннотация}

В статье рассматриваются значения внутреннего аудита для хозяйствующего субъекта, варианта его организации и критерии оценки эффективности.

Ключевые слова: внутренний аудит, функции, задачи, эффективность.

\section{Abstract}

The article considers the importance of internal audit for business entity, the version of its organization and criteria for evaluating its effectiveness.

Keywords: internal audit, functions, goals, tffectiveness.

В экономически развитых странах хозяйствующие субъекты уделяют внутреннему аудиту не менее пристальное внимание, чем внешнему аудиту.

Законодательно в РФ закреплена только обязанность организации хозяйствующими субъектами внутреннего контроля совершаемых фактов хозяйственной жизни в ст. 19 ФЗ- 